\title{
Osmotic stress decreases aquaporin-4 expression in the human retinal pigment epithelial cell line, ARPE-19
}

\author{
FRANÇOIS WILLERMAIN ${ }^{1,2}$, SARAH JANSSENS ${ }^{1,3}$, TATJANA ARSENIJEVIC ${ }^{3}$, ISABELLE PIENS ${ }^{3}$, \\ NARGIS BOLAKY ${ }^{3}$, LAURE CASPERS $^{1}$, JASON PERRET $^{3}$ and CHRISTINE DELPORTE ${ }^{3}$ \\ ${ }^{1}$ Department of Ophthalmology, CHU Saint-Pierre and Brugmann; ${ }^{2}$ Institut de Recherche \\ Interdisciplinaire en Biologie Humaine et Moléculaire (IRIBHM), ${ }^{3}$ Laboratory of Pathophysiological \\ and Nutritional Biochemistry, Université Libre de Bruxelles, Brussels, Belgium
}

Received December 9, 2013; Accepted May 20, 2014

DOI: $10.3892 /$ ijmm.2014.1791

\begin{abstract}
The regulation of water movement is of utmost importance for normal retinal function. Under physiological conditions, water is transported, dependent on the osmotic gradient, through the retinal pigment epithelial cell layer from the subretinal space to the choroid. The osmotic gradient has been found to be modified in eye diseases, thus leading to water accumulation in the subretinal space and the sensory retina, and subsequently contributing to the formation of macular oedema. Understanding the regulation of aquaporin expression is therefore crucial. In this study, we investigated the effects of hyperosmolarity on aquaporin-4 (AQP4) protein expression in the human retinal pigment epithelial cell line, ARPE-19. AQP4 expression was examined by PCR, western blot analysis and immunofluorescence. Ubiquitinylation was examined by immunoprecipitation. The results revealed that hyperosmotic stress rapidly decreased AQP4 expression in the ARPE-19 cells. The effect remained unmodified by lysosomal or mitogen-activated protein kinase inhibitors, but was reversed by proteasome inhibitors. However, no ubiquitinylation of AQP4 was detected. Our results suggest that hyperosmotic stress markedly reduces AQP4 expression possibly through a proteasome ubiquitinylation-independent pathway. This may represent an adaptation to hyperosmotic stress. The results presented in this study contribute to our understanding of the formation of macular oedema.
\end{abstract}

\section{Introduction}

The blood-retinal barrier (BRB) regulates water, solutes and ion fluxes in the retina. The inner BRB is mainly the result

Correspondence to: Professor Christine Delporte, Laboratory of Pathophysiological and Nutritional Biochemistry, Université Libre de Bruxelles, 808 Route de Lennik, Blg G/E - CP611, B-1070 Brussels, Belgium

E-mail: cdelport@ulb.ac.be

Key words: aquaporin-4, retinal pigment epithelial cells, protein degradation, osmotic stress, cell of the isolation of the retina by the tight junctions of retinal endothelial cells $(1,2)$. Müller cell extensions surrounding retinal blood vessels contribute to the tightness of the inner BRB. The outer BRB relies on retinal pigment epithelial (RPE) cell tight junctions, which impede paracellular flow, and ionic pumps and channels that create a transepithelial osmotic gradient. Water follows down this gradient and flows from the subretinal space to the choroid through RPE cells (3). The exact mechanisms through which water penetrates RPE cells remain elusive. Aquaporins (AQPs), the water-specific membrane channels, may be responsible for this function $(4,5)$. Hence, it has been reported that human RPE cells express, among several AQPs (6,7), aquaporin-4 (AQP4) (6). AQP4 is abundantly expressed in the brain and is involved in the pathophysiological mechanisms leading to brain oedema $(8,9)$. On the other hand, in the inner BRB, AQP4 expression in Müller cells is associated with water transport $(1,10,11)$.

Fluid accumulation into the retina leads to the formation of macular oedema, a hallmark of severe retinal diseases and one of the leading causes of central vision loss in developed countries. It has been demonstrated that macular oedema results in the disruption of the BRB, leading to the accumulation of proteins and solutes close to the RPE layer, thus increasing hyperosmolarity, leading to the accumulation of water into the retina $(12,13)$. It is therefore postulated that RPE cells undergo hyperosmotic stress during macular oedema.

Hyperosmolarity modulates AQP expression in various cell types. Hence, it increases the expression of several AQPs, such as AQP1 (14-16), AQP2 (16-18), AQP3 (19,20), AQP4 (21), AQP5 (22-27) and AQP9 (21), and induces AQP4 downregulation during the formation of oedema in the brain cortex (28). Several mechanisms account for these changes in AQP expression, including the simultaneous activation of the three main mitogen-activated protein kinases (MAPKs), ERK, p38 kinase and JNK, as well as the activation of transcription factors $(27,29)$. Several AQP proteins are also degraded through lysosomal or proteasome pathways $(30,31)$.

As RPE cells are likely to undergo hyperosmotic stress during macular oedema and AQP4 is expressed in human RPE cells, in this study, we investigated the effects of hyperosmolarity on AQP4 protein expression in the human retinal pigment epithelial cell line, ARPE-19. 


\section{Materials and methods}

Reagents and antibodies. Dulbecco's modified Eagle's medium (DMEM; $4.5 \mathrm{~g} / \mathrm{l}$ glucose), streptomycin/penicillin and fetal bovine serum were obtained from Invitrogen Life Technologies (Carlsbad, CA, USA). MG132, chloroquine, calpain and calpeptin were purchased from Sigma (St. Louis, MO, USA). Anti-phospho p38 and anti-ubiquitin antibodies were from Cell Signaling Technology, Inc. (Danvers, MA, USA) and Pierce Biotechnology, Inc. (Rockford, IL, USA), respectively. Antibodies against glucose transporter 1 (Glut1) were from Millipore (Billerica, MA, USA). SB203580, SB202474 and anisomycin were from EDM-Millipore.

Cell culture. Human ARPE-19 cells were grown in DMEM/ HAM-F12 medium containing 10\% foetal calf serum, $100 \mathrm{UI} /$ $\mathrm{ml}$ streptomycin-penicillin and $4 \mathrm{mM}$ glutamine, and were passaged twice a week. The cells were treated for different periods of time (10,30 and $60 \mathrm{~min})$ with a control medium or a hyperosmotic medium containing an additional $200 \mathrm{mM} \mathrm{NaCl}$ or $400 \mathrm{mM}$ sucrose (osmotic stress). In some experiments, the ARPE-19 cells were pre-treated for $1 \mathrm{~h}$ in the absence or presence of inhibitors of lysosomes, the proteasome, p38 kinase, MAPK/ERK kinase or activator of p38 kinase.

$R T-P C R$. Total RNA from the ARPE-19 cells was extracted using the Aurum ${ }^{\mathrm{TM}}$ total RNA kit (Bio-Rad, Hercules, CA, USA) and verified for its quality using the Experion automated electrophoresis system (Bio-Rad). The RNA was then reverse transcribed into cDNA using a RevertAid ${ }^{\mathrm{TM}}$ first-strand cDNA synthesis kit (Fermentas, St. Leon-Rot, Germany). The primers used for the amplification of human AQP4 cDNA were 5'-GGAATTTCTGGCCATGCTTA-3' and 5'-AGACTTGGCG ATGCTGATCT-3' and for $\beta$-actin cDNA were 5 '-TGACGGGG TCACCCACACTGTGCCCGTC-3' and 5'-CTAGAAGCA TTAGCGGTGGACGATGGAGG-3' (amplicons, 226 and $661 \mathrm{bp})$. The PCR reactions were performed in $20 \mu \mathrm{l}$ reaction volume containing $1 \mu \mathrm{l}$ of cDNA, $0.5 \mathrm{U}$ GoTaq DNA polymerase (Promega, Madison, WI, USA), $0.2 \mathrm{mM}$ dNTP, $0.5 \mu \mathrm{M}$ of each primer and $4 \mu \mathrm{l} \mathrm{GoTaq} \mathrm{Green} \mathrm{buffer} \mathrm{using} \mathrm{the}$ iCycler Thermocycler (Bio-Rad). PCR conditions were $94^{\circ} \mathrm{C}$ for $3 \mathrm{~min}$ followed by 35 cycles of $30 \mathrm{sec}$ at $95^{\circ} \mathrm{C}, 30 \mathrm{sec}$ at $57^{\circ} \mathrm{C}$ and $1 \mathrm{~min}$ at $72^{\circ} \mathrm{C}$. PCR products were subjected to electrophoresis in a $1.5 \%$ agarose gel. Direct sequencing of the AQP4 PCR was performed.

Isolation of polyubiquitinated proteins. Polyubiquitinated proteins were isolated from total protein from ARPE-19 cells (see below) using an ubiquitin enrichment kit (Pierce) following the manufacturer's instructions. Briefly, $150 \mu \mathrm{g}$ of total protein from the ARPE-19 cells were subjected to a highbinding affinity resin allowing the binding of polyubiquitinated proteins. The polyubiquitinated proteins were then eluted and subjected to western blot analysis using either anti-ubiquitin or anti-AQP4 antibodies.

Western blot analysis. Crude plasma membrane protein or total protein from the ARPE-19 cells was analyzed by SDS-PAGE in the presence of $5 \% \beta$-mercaptoethanol using $12 \%$ polyacrylamide gels. For crude plasma membrane protein preparation,
$2 \mathrm{ml}$ of $1 \mathrm{mM} \mathrm{NaHCO}$ containing a protease inhibitor cocktail (Complete EDTA free; Roche Diagnostics GmbH, Mannheim, Germany) was added to a $\varnothing 10 \mathrm{~cm}$ plate of ARPE- 19 cells prior to harvest and immediate freezing in liquid nitrogen. The disrupted cells were subjected to a 10-min centrifugation at $1,250 \times \mathrm{g}$ at $4^{\circ} \mathrm{C}$; the supernatant was subjected to a further 20 -min centrifugation at $25,000 \mathrm{xg}$ at $4^{\circ} \mathrm{C}$, and the pellet was resuspended in $50 \mathrm{mM}$ Tris- $\mathrm{HCl}, \mathrm{pH} 7.4$, containing protease inhibitors (Complete EDTA free; Roche Diagnostics GmbH). For total protein preparation, the cells were washed with calcium- and magnesium-free PBS and lysed in $50 \mathrm{mM}$ Tris- $\mathrm{HCl}$ (pH 7.5), $150 \mathrm{mM} \mathrm{NaCl}, 0.5 \% \mathrm{NP}-40,50 \mathrm{mM} \mathrm{NaF}, 1 \mathrm{mM}$ sodium orthovanadate, and dithiothreitol and protease inhibitors (complete EDTA free, Roche Diagnostics GmbH). The proteins were transferred onto PVDF membranes and immunolabeled using specific antibodies against AQP4 (see above, dilution, 1:1,000), Glut1 (1:100,000; used as a loading control), anti-phospho p38 (dilution, 1:1,000), anti-ubiquitin (dilution, 1:7,500). Bound antibodies were detected using the ECL chemiluminescence method (GE Healthcare, Little Chalfont, UK). The AQP4 antibody, obtained from rabbit immunization using a synthetic peptide corresponding to amino acids 301-318 of mouse AQP4 (89\% identity to the human AQP4 sequence), was affinity purified, and its specificity was verified.

Immunofluorescence. The ARPE-19 cells were grown on gelatinized glass covers, fixed in $4 \%$ paraformaldehyde (PAF), permeabilized with $100 \%$ methanol for $10 \mathrm{~min}$ at $4^{\circ} \mathrm{C}$, then successively incubated with $10 \%$ horse serum for $60 \mathrm{~min}$, primary antibodies [anti-AQP4 and anti-pan-cytokeratin (Sigma-Aldrich)] overnight at $4^{\circ} \mathrm{C}$, biotinylated anti-rabbit IgG (1/200; GE Healthcare) and streptavidin-cyanine 2 (1/300; Jackson ImmunoResearch, West Grove, PA, USA) and/or anti-mouse IgG coupled to cyanine 3 for $60 \mathrm{~min}$. The cells were mounted using ProLong Gold Antifade reagent with DAPI (Invitrogen Life Technologies). For the negative controls, the primary antibody was omitted. Images were acquired using an AxioCam MRB fluorescent microscope using a x40 objective (Carl Zeiss, Jena, Germany).

\section{Results}

Expression of AQP4 in ARPE-19 cells. AQP4 was expressed in the ARPE-19 cells. RT-PCR of AQP4 and $\beta$-actin using human kidney cDNA as a positive control and ARPE-19 cell cDNA revealed a unique amplicon of expected size, i.e., 225 and $660 \mathrm{bp}$, respectively, while no amplicons were detected in the negative non-target control (Fig. 1A). Western blot analysis of the crude plasma membrane proteins of human kidney, used as a positive control, and of the ARPE-19 cells revealed the presence of AQP4 protein (Fig. 1B). AQP4 was detected by immunofluorescence in pancytokeratin-positive ARPE-19 cells (Fig. 1C).

Decreased AQP4 expression observed in response to osmotic stress. As early as $10 \mathrm{~min}$ following hyperosmotic stimulation with $200 \mathrm{mM} \mathrm{NaCl}$ or $400 \mathrm{mM}$ sucrose, membrane AQP4 protein expression was markedly decreased and seemed to reach its minimum 30-60 min post-stimulation (Fig. 2). The expression of Glut1, used a loading control, was not modified by the hyperosmotic stimulations (Fig. 2). 
A

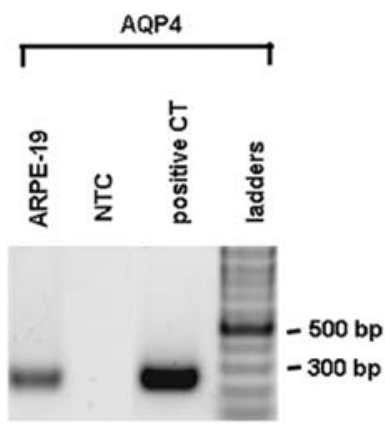

B

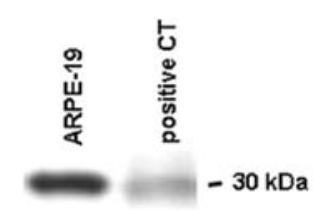

C
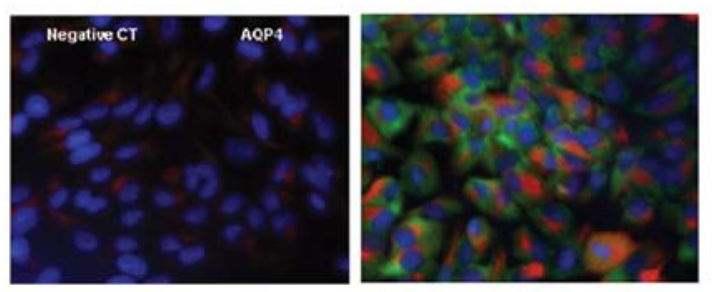

Figure 1. Expression of aquaporin-4 (AQP4) in ARPE-19 cells. (A) RT-PCR of AQP4 and $\beta$-actin. ARPE-19, ARPE-19 cDNA; NTC, negative non-target control using PCR water instead of cDNA; positive CT, positive control using human kidney cDNA; ladders, DNA ladders. (B) Western blot analysis for detection of AQP4 in ARPE-19 cells or human kidney cDNA (positive control). (C) Detection of AQP4 by double immunofluorescence in ARPE-19 cells. AQP4 (in green), pancytokeratin (a marker of epithelial cells; in red), and cell nuclei (in blue) labelling. Negative CT, negative control (absence of primary antibody).

Degradative pathways are involved in the decrease in AQP4 expressionfollowing exposure to osmotic stress. Pre-incubation of the cells with the lysosomal inhibitor, chloroquine (100 $\mu \mathrm{M})$, or the calpain (a non-lysosomal cysteine protease) inhibitor, calpeptin $(50 \mu \mathrm{M})$, had no effect on the decrease in total AQP4 protein expression induced by $4 \mathrm{~h}$ of exposure to osmotic stress (Fig. 3A). By contrast, pre-treatment of the cells with the proteasome inhibitor, MG132 $(10 \mu \mathrm{M})$, prior to $4 \mathrm{~h}$ of exposure to osmotic stress, markedly restored AQP4 protein expression under both $\mathrm{NaCl}$ and sucrose stimulation (Fig. 3B). The expression of Glut1, used as a loading control, was not modified under these conditions (Fig. 3A and B). Therefore, the proteasome is likely to be involved in AQP4 degradation.

Ubiquitinylation is not likely to be involved in AQP4 degradation by the proteasome. Following the exposure of the ARPE-19 cells to osmotic stress, polyubiquitinated proteins, purified from total ARPE-19 cell proteins, were subjected to western blot analysis using anti-ubiquitin and anti-AQP4 antibodies. The use of anti-ubiquitin antibodies revealed a diffuse pattern of bands that increased in the presence of MG132 as

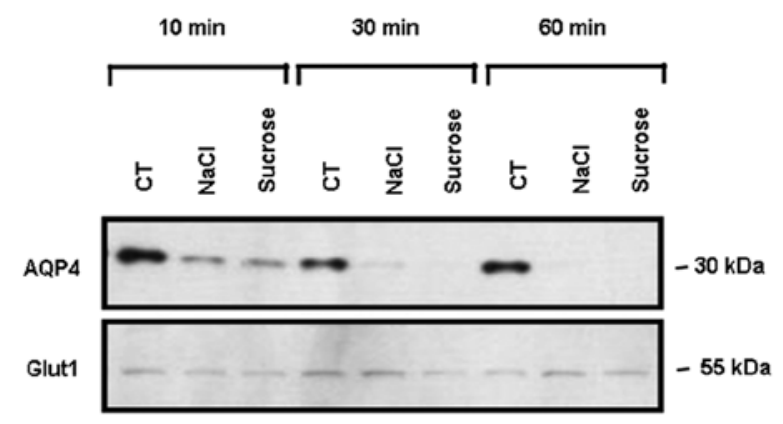

Figure 2. Decreased aquaporin-4 (AQP4) expression in response to hyperosmotic stress. ARPE-19 cells were incubated for various periods of time $(10,30$ and $60 \mathrm{~min})$ in the absence $(\mathrm{CT}$, control) or presence of $200 \mathrm{mM}$ $\mathrm{NaCl}$ or $400 \mathrm{mM}$ sucrose. Membrane AQP4 expression was then detected by western blot analysis using $5 \mu \mathrm{g}$ of protein per lane. Detection of Glut1 was used as a loading control. The data are representative of at least 3 independent experiments.

A

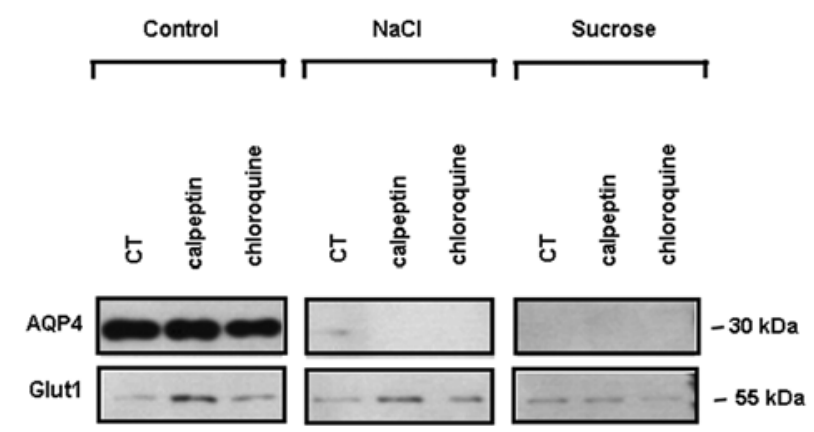

B

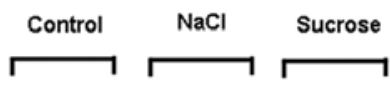

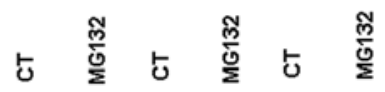

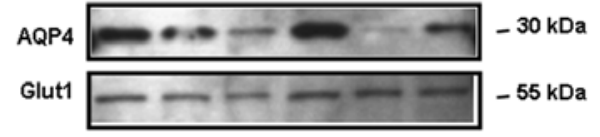

Figure 3. Degradative pathways involved in the decrease of aquaporin-4 (AQP4) expression following exposure to osmotic stress. ARPE-19 cells were pre-incubated for $1 \mathrm{~h}$ with the agents and then further incubated for $4 \mathrm{~h}$ in the absence (control) or presence of $200 \mathrm{mM} \mathrm{NaCl}$ or $400 \mathrm{mM}$ sucrose. AQP4 expression was then detected by western blot analysis using $5 \mu \mathrm{g}$ of total protein per lane. (A) Effects of $\mathrm{H}_{2} \mathrm{O}$, DMSO and of the inhibitors of lysosomal activities, calpeptin and chloroquine (dissolved in DMSO), on AQP4 expression. (B) Effects of $\mathrm{H}_{2} \mathrm{O}$, DMSO and of the inhibitor of the proteasome, MG132 (dissolved in DMSO), on AQP4 expression. Detection of Glut1 was used as a loading control. The data are representative of at least 3 independent experiments.

compared to its absence in both the unstimulated (control) and stimulated ( $\mathrm{NaCl}$ and sucrose) ARPE-19 cells. The accumulation of ubiquitinylated proteins observed in the presence of MG132 indicated that it effectively inhibited the proteasome. The use of anti-AQP4 antibodies did not reveal any diffuse pattern of bands in the absence or presence of MG132 in both 


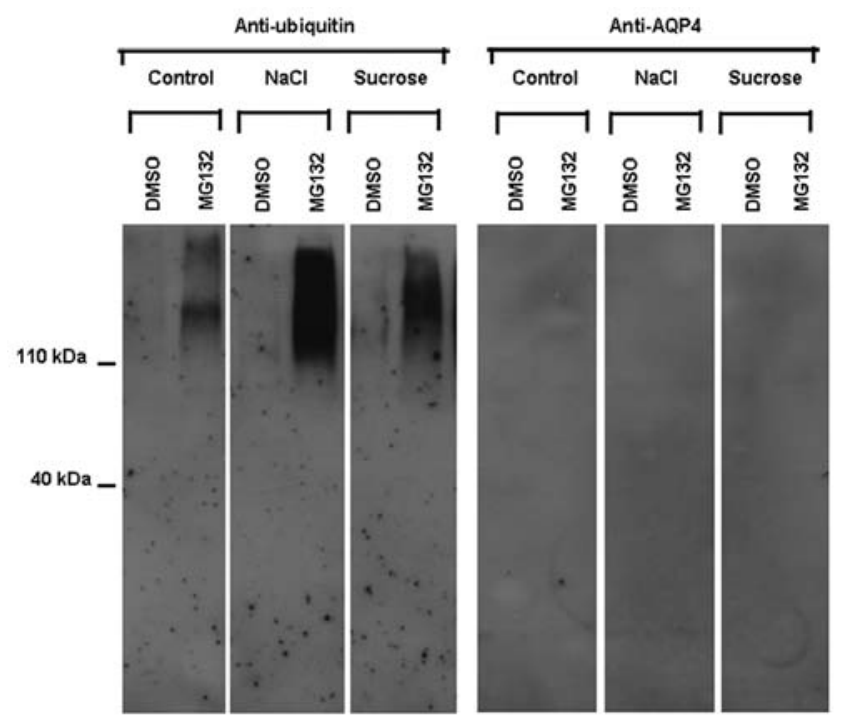

Figure 4. Ubiquitinylation is unlikely to be involved in aquaporin-4 (AQP4) degradation by the proteasome. ARPE-19 cells were unstimulated (control) or stimulated with $200 \mathrm{mM} \mathrm{NaCl}$ or $400 \mathrm{mM}$ sucrose for $4 \mathrm{~h} .150 \mu \mathrm{g}$ of total protein from ARPE-19 cells were subjected to a high-binding affinity resin allowing the binding of polyubiquitinated proteins. The isolated ARPE-19 polyubiquitinated proteins were then subjected to western blot analysis using anti-ubiquitin or anti-AQP4 antibodies. The data are representative of 3 independent experiments.

the unstimulated (control) and stimulated $(\mathrm{NaCl}$ and sucrose) ARPE-19 cells (Fig. 4).

p38 activation following exposure to osmotic stress. In response to $4 \mathrm{~h}$ of exposure to osmotic stress $(200 \mathrm{mM} \mathrm{NaCl}$ and $400 \mathrm{mM}$ sucrose), the MAPK pathway was activated in the ARPE-19 cells, as revealed by the detection of p38 activation using an anti-phospho p38 antibody specifically recognizing the active double-phosphorylated protein (Fig. 5A). However, $1 \mu \mathrm{M}$ SB203580, a p38 kinase inhibitor and $1 \mu \mathrm{M}$ SB202474 (an inactive analog of SB203580), as well as $10 \mu \mathrm{M}$ UO126, an inhibitor of MAPK/ERK kinase, had no effect on the decrease in AQP4 expression following exposure to osmotic stress (Fig. 5B and C). Furthermore, the presence of a p38 activator $(10 \mu \mathrm{g} / \mathrm{ml}$ anisomycin) for $4 \mathrm{~h}$ had no effect on AQP4 expression in ARPE-19 cells incubated under the control conditions (Fig. 5B).

\section{Discussion}

Tightly regulated water movements through RPE cells are required for normal retinal function. Under several pathophysiological situations, the osmotic gradient is modified and water consequently accumulates in the subretinal space and the sensory retina, leading to the formation of macular oedema.

Although it is accepted that water passes through RPE cells, the exact molecular mechanisms responsible for this flux remain elusive. As AQPs are recognized water channels, it seems likely that the expression of AQPs in RPE cells may play an important role in this phenomenon. Human RPE cells appear to express several AQPs (6,7), including AQP4 (6). These data prompted us to investigate the expression of AQP4
A

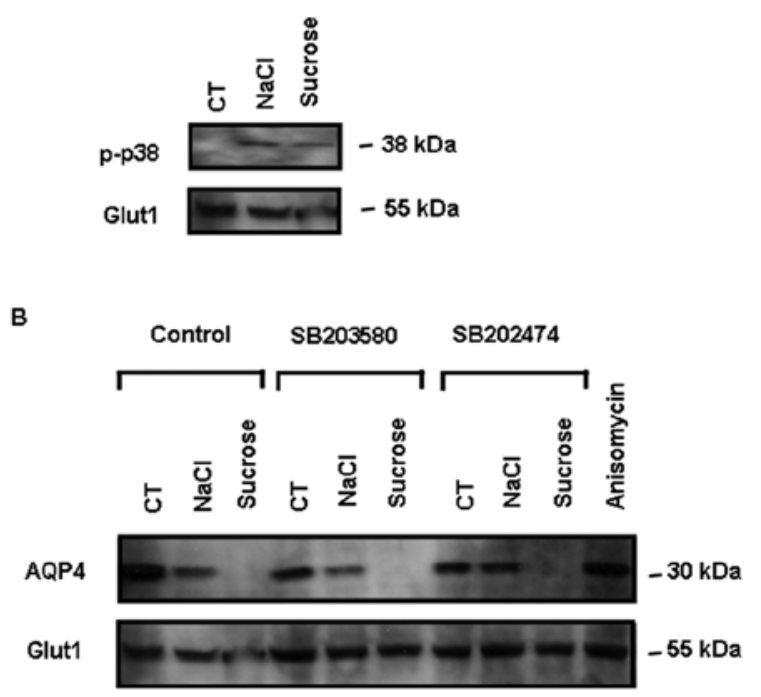

C
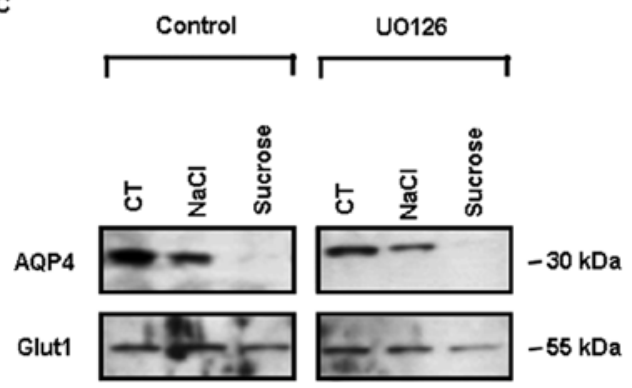

Figure 5. p38 activation following osmotic stress was not found to be responsible for the decrease in aquaporin-4 (AQP4) expression. (A) Phosphorylated p38 (p-p38) expression was detected by western blot analysis using $5 \mu \mathrm{g}$ of protein from the ARPE-19 cells incubated in the absence (CT, control) or presence or $200 \mathrm{mM} \mathrm{NaCl}$ or $400 \mathrm{mM}$ sucrose. (B) AQP4 expression was detected by western blot analysis using $5 \mu \mathrm{g}$ of protein from the ARPE-19 cells incubated for $4 \mathrm{~h}$ in the absence (CT) or presence of $1 \mu \mathrm{M} \mathrm{SB} 203580$ (a p38 kinase inhibitor), or $1 \mu \mathrm{M}$ SB202474 (an inactive analog of SB203580), or $10 \mu \mathrm{g} / \mathrm{ml}$ anisomycin (an activator of p38). (C) AQP4 expression was detected by western blot analysis using $5 \mu \mathrm{g}$ of protein from the ARPE-19 cells incubated for $4 \mathrm{~h}$ in the absence (CT) or presence of $10 \mu \mathrm{M} \mathrm{UO126}$ (a MAPK/ERK kinase inhibitor). Detection of Glut1 was used as a loading control. The data are representative of 3 independent experiments.

and its regulation following hyperosmotic stress stimulation in the human ARPE-19 cell line. We found that the ARPE-19 cells indeed expressed AQP4 at the mRNA and protein level.

Based on the fact that osmotic pressure is the main force involved in water movement, we hypothesized that osmotic stress may affect AQP4 expression in ARPE-19 cells. Indeed, upon hyperosmotic stress stimulation, we observed a rapid decrease in AQP4 expression that was found to be more pronounced following stimulation with sucrose than with $\mathrm{NaCl}$. Since an inhibitor of the proteasome, MG132, blocked AQP4 degradation upon hyperosmotic stress, it is likely that this degradation occurs through the proteasome.

Despite their possible exposure to extreme hyperosmotic stress, cells can survive and function owing to protective adaptation, including the accumulation of large amounts of organic osmolytes that normalize cell volume and intracellular ionic 
strength. In RPE cells, it has been shown that hyperosmolarity regulates aldose reductase activity, and taurine transporter expression and function $(32,33)$.

In other tissues and cells, hyperosmolarity has generally been reported to increase the expression of several AQPs (14-20,22-29,23,34). By contrast, in ARPE-19 cells, a decreased AQP4 protein expression was observed in response to the hyperosmotic stress induced by $200 \mathrm{mM} \mathrm{NaCl}$ and $400 \mathrm{mM}$ sucrose using both membrane protein (Fig. 2) and total protein (Fig. 3). Therefore, the reduced membrane AQP4 expression is unlikely due to the decreased insertion of AQP4 into the membrane. Our results are in agreement with those of a previous study, which demonstrated a decrease in AQP4 expression observed in response to hyperosmotic stress during oedema formation in the contusional brain cortex (28).

The activation of p38 (21) or ERK (24) has been considered to be essential for the induction of adaptative responses to osmotic stress (35) and the increased expression of several AQPs in response to hyperosmotic stress. However, despite the simultaneous activation of the three MAPKs (ERK, p38 kinase and JNK) $(14,18)$, these mechanisms do not seem to account for the decreased AQP4 protein expression in response to hyperosmotic stress in ARPE-19 cells. Indeed, our data demonstrated that the pre-incubation of ARPE-19 cells with inhibitors of these kinases did not affect the decrease in AQP4 protein expression in response to the subsequent hyperosmotic stress.

Some AQP proteins have also been shown to be the target for proteolysis through lysosomal degradation (16,30,31,36-38). However, in our study, the lysosomal pathway did not appear to participate in the protein degradation of AQP4 in ARPE-19 cells subjected to hyperosmotic stress. Indeed, the lysosomal protease inhibitors, calpeptin and chloroquine, had no effect on the decrease in AQP4 protein levels observed in response to hyperosmotic stress.

The ubiquitinylation (39-42) and proteasomal degradation $(16,31,36)$ of several AQPs has been previously described. The proteasomal pathway may participate in the protein degradation of AQP4 in ARPE-19 cells subjected to hyperosmotic stress, as MG132, an inhibitor of the proteasome, prevented the decrease in the AQP4 protein level in response to hyperosmotic stress. Our data are in agreement with those of a previous study which demonstrated the presence of an active ubiquitinproteasome pathway in ARPE-19 cells as anti-ubiquitin antibodies detected a diffuse pattern of bands that increased in the presence of MG132 (43). However, no apparent AQP4 ubiquitinylation could be detected in the absence or presence of hyperosmotic stress under our experimental conditions, as anti-AQP4 antibodies did not reveal any bands following polyubiquitinated protein enrichment. Therefore, AQP4 is likely to be degraded in a ubiquitin-independent manner by the proteasome as described for other proteins, such as ornitine decarboxylase, $\mathrm{p} 53, \mathrm{p} 21^{\text {Cip }}$, steroid receptor coactivator, $\mathrm{p} 300$ or nuclear factor of activated T cells 5 (NFAT5) (44-49). However, we cannot rule out the possibility that if ubiquitinylation occurs in one or several of the three lysine residues present in the AQP4 C-terminal peptide sequence used to produce the antibodies, this would impair the peptide epitope recognition by the antibodies. Further proteomic studies are required to undoubtedly confirm the absence or presence of ubiquitinylated AQP4 in response to hyperosmotic stress.
The decreased AQP4 protein expression observed in the ARPE-19 cells under osmotic stress may reflect one of the underlying pathophysiological mechanisms occurring during the formation of macular oedema and/or a protective/adaptative mechanism in response to the hyperosmotic cellular stress occurring during the formation of macular oedema.

In conclusion, hyperosmotic stress in the ARPE-19 cells induced a marked decrease in AQP4 expression due to AQP4 protein degradation by the proteasome that is possibly independent of ubiquitinylation.

\section{Acknowledgements}

This study was supported by the Fund for Medical Scientific Research (FRSM, Belgium; grant no. 3.4502.09) and the Funds for Research in Ophthalmology (FRO, Belgium). S.J. is a recipient of a Vésale Foundation Award; T.A. is a recipient of a FNRS fellowship (FNRS, Belgium).

\section{References}

1. Bringmann A, Reichenbach A and Wiedemann P: Pathomechanisms of cystoid macular edema. Ophthalmic Res 36: 241-249, 2004.

2. Bringmann A, Uckermann O, Pannicke T, Iandiev I, Reichenbach A and Wiedemann P: Neuronal versus glial cell swelling in the ischaemic retina. Acta Ophthalmol Scand 83: $528-538,2005$.

3. Strauss O: The retinal pigment epithelium in visual function. Physiol Rev 85: 45-881, 2005.

4. Agre P: Aquaporin water channels (Nobel Lecture). Angew Chem Int Ed Engl 43: 4278-4290, 2004.

5. Verkman AS: Role of water channels in eye function. Exp Eye Res 76: 137-143, 2003

6. Hollborn M, Rehak M, Iandiev I Pannicke T, Ulbricht E, Reichenbach A, Wiedemann P, Bringmann A and Kohen L: Transcriptional regulation of aquaporins in the ischemic rat retina: upregulation of aquaporin 9. Curr Eye Res 37: 514-531, 2012.

7. Stamer WD, Bok D, Hu J, Jaffe GJ and McKay BS: Aquaporin-1 channels in human retinal pigment epithelium: role in transepithelial water movement. Invest Ophthalmol Vis Sci 44: 2803-2808, 2003.

8. Badaut J, Ashwal S and Obenaus A: Aquaporins in cerebrovascular disease: a target for treatment of brain edema? Cerebrovasc Dis 31: 521-531, 2011.

9. Papadopoulos MC and Verkman AS: Aquaporin-4 and brain edema. Pediatr Nephrol 22: 778-784, 2007.

10. Da T and Verkman AS: Aquaporin-4 gene disruption in mice protects against impaired retinal function and cell death after ischemia. Invest Ophthalmol Vis Sci 45: 4477-4483, 2004.

11. Nagelhus EA, Veruki ML, Torp R, Haug FM, Laake JH, Nielsen S, Agre P and Ottersen OP: Aquaporin-4 water channel protein in the rat retina and optic nerve: polarized expression in Muller cells and fibrous astrocytes. J Neurosci 18: 2506-2519, 1998.

12. Marmor MF and Tan F: Central serous chorioretinopathy: bilateral multifocal electroretinographic abnormalities. Arch Ophthalmol 117: 184-188, 1999.

13. Soliman W, Sander B and Jorgensen TM: Enhanced optical coherence patterns of diabetic macular oedema and their correlation with pathophysiology. Acta Ophthalmol 85: 613-617, 2005.

14. Umenishi F and Schrier RW: Hypertonicity-induced aquaporin-1 (AQP1) expression is mediated by the activation of MAPK pathways and hypertonicity-responsive element in the AQP1 gene. J Biol Chem 278: 15765-15770, 2003.

15. Umenishi F, Narikiyo T and Schrier RW: Hypertonic induction of aquaporin-1 water channel independent of transcellular osmotic gradient. Biochem Biophys Res Commun 325: 595-599, 2004.

16. Umenishi F, Narikiyo T and Schrier RW: Effect on stability, degradation, expression, and targeting of aquaporin-2 water channel by hyperosmolality in renal epithelial cells. Biochem Biophys Res Commun 338: 1593-1599, 2005. 
17. Hasler U, Nunes P, Bouley R, Lu HAJ, Matsuzaki T and Brown D: Acute hypertonicity alters aquaporin-2 trafficking and induces a MAPK-dependent accumulation at the plasma membrane of renal epithelial cells. J Biol Chem 283: 26643-26661, 2008.

18. Hasler U: Controlled aquaporin-2 expression in the hypertonic environment. Am J Physiol 296: C641-C653, 2009.

19. Matsuzaki T, Suzukin T and Takata K: Hypertonicity-induced expression of aquaporin 3 in MDCK cells. Am J Physiol 281: C55-C63, 2001.

20. Sugiyama Y, Ota $Y$, Hara M and Inoue S: Osmotic stress up-regulation of aquaporin-3 expression in cultured human keratinocytes. Biochim Biophys Acta 1522: 82-88, 2001.

21. Arima H, Yamamoto N, Sobue K, Umenishi F, Tada T, Katsuya H and Asai K: Hyperosmolar mannitol simulates expression of aquaporins 4 and 9 through a p38 mitogen-activated protein kinase-dependent pathway in rat astrocytes. J Biol Chem 278: 44525-44534, 2003.

22. Hansen AK and Galtung HK: Aquaporin expression and cell volume regulation in the SV40 immortalized rat submandibular acinar cell line. Pflugers Arch 453: 787-796, 2007.

23. Herrlich A, Leitch V and King LS: Role of proneuregulin 1 cleavage and human epidermal growth factor receptor activation in hypertonic aquaporin induction. Proc Natl Acad Sci USA 101: 15799-15804, 2004.

24. Hoffert JD, Leitch V, Agre P and King LS: Hypertonic induction of aquaporin-5 expression through an ERK-dependent pathway. J Biol Chem 275: 9070-9077, 2000.

25. Hwang SM, Lee RH, Song JM, Yoon S, Kim YS, Lee SJ, Kang SK and Jung JS: Expression of aquaporin-5 and its regulation in skeletal muscle cells. Exp Mol Med 34: 69-74, 2002.

26. Pedersen PS, Braunstein TH, Jorgensen A, Larsen PL, Holstein-Rathlou NH and Frederiksen O: Stimulation of aquaporin-5 and transepithelial water permeability in human airway epithelium by hyperosmotic stress. Pflugers Arch 453: 777-785, 2007

27. Zhou B, Ann DK, Li X, Kim KJ, Lin H, Minoo P, Crandall ED and Borok Z: Hypertonic induction of aquaporin-5: novel role of hypoxia-inducible factor-1alpha. Am J Physiol 292: C1280-C1290, 2007.

28. Ke C, Poon WS, Ng HK, Pang JCS and Chan Y: Heterogeneous responses of aquaporin-4 in oedema formation in a replicated severe traumatic brain injury model in rats. Neurosci Lett 301: 21-24, 2001.

29. Kasono K, Saito T, Saito T, Tamemoto H, Yanagidate C, Uchida S, Kawakami M, Sasaki S and Ishikawa SE: Hypertonicity regulates the aquaporin-2 promoter independently of arginine vasopressin. Nephrol Dial Transplant 20: 509-515, 2005.

30. Gan SW, Ran JH, Chen H, Ren ZQ, Sun SQ, Zhu SJ, Lu WT, Xu J, Zhang B, Huang J, Wang KJ and Chen Z: Lysosomal degradation of retinal glial AQP4 following its internalization induced by acute ocular hypertension. Neurosci Lett 516: 135-140, 2012.

31. Hasler U,Mordasini D, Bens M, Bianchi M, Cluzeaud F, Rousselot M, Vandewalle A, Feraille E and Martin PY: Long term regulation of aquaporin-2 expression in vasopressin-responsive renal collecting duct principal cells. J Biol Chem 277: 10379-10386, 2002.

32. El Sherbeny A, Naggar H, Miyauchi S, Ola MS, Maddox DM, Martin PM, Ganapathy V and Smith SB: Osmoregulation of taurine transporter function and expression in retinal pigment epithelial, ganglion, and Muller cells. Invest Ophthalmol Vis Sci 45: 694-701, 2004.
33. Lin LR, Carper D, Yokoyama T and Reddy VN: The effect of hypertonicity on aldose reductase, alpha B-crystallin, and organic osmolytes in the retinal pigment epithelium. Invest Ophthalmol Vis Sci 34: 2352-2359, 1993.

34. Storm R, Klussmann E, Geelhaar A, Rosenthal W and Maric K: Osmolality and solute composition are strong regulators of AQP2 expression in renal principal cells. Am J Physiol 284: F189-F198, 2003.

35. de Nadal E, Alepuz PM and Posas F: Dealing with osmostress through MAP kinase activation, EMBO Rep 3: 735-740, 2002.

36. Lehmann GL, Larocca MC, Soria LR and Marinelli RA Aquaporins: their role in cholestatic liver disease. World J Gastroenterol 14: 7059-7067, 2008

37. Madrid R, Le Maout S, Barrault MB, Janvier K, Benichou S and Merot J: Polarized trafficking and surface expression of the AQP4 water channel are coordinated by serial and regulated interactions with different clathrin-adaptor complexes. EMBO J 20: 7008-7021, 2001.

38. Sidhaye V, Hoffert JD and King LS: cAMP has distinct acute and chronic effects on aquaporin-5 in lung epithelial cells. J Biol Chem 280: 3590-3596, 2005 .

39. Dibas A, Yang MH, He S, Bobich J and Yorio T: Changes in ocular aquaporin-4 (AQP4) expression following retinal injury. Mol Vis 14: 1770-1783, 2008

40. Kamsteeg EJ, Hendriks G, Boone M, Konings IBM, Oorschot V, van der Sluijs P, Klumperman J and Deen PM: Short-chain ubiquitination mediates the regulated endocytosis of the aquaporin-2 water channel. Proc Natl Acad Sci USA 103 18344-18349, 2006.

41. Leitch V, Agre P and King LS: Altered ubiquitination and stability of aquaporin-1 in hypertonic stress. Proc Natl Acad Sci USA 98: 2894-2898, 2001.

42. Schweitzer K, LiE, Sidhaye V,Leitch V, Kuznetsov S and King LS: Accumulation of aquaporin-1 during hemolysin-induced necrotic cell death. Cell Mol Biol Lett 13: 195-211, 2008.

43. Fernandes AF, Guo W, Zhang X, Gallagher M, Ivan M, Taylor A, Pereira $\mathrm{P}$ and Shang F: Proteasome-dependent regulation of signal transduction in retinal pigment epithelial cells. Exp Eye Res 83: 1472-1481, 2006.

44. Asher G, Tsvetkov P, Kahana C and Shaul Y: A mechanism of ubiquitin-independent proteasomal degradation of the tumor suppressors p53 and p73. Genes Dev 19: 316-321, 2005.

45. Ito T, Fujio Y, Takahashi K and Azuma J: Degradation of NFAT5, a transcriptional regulator of osmotic stress-related genes, is a critical event for doxorubicin-induced cytotoxicity in cardiac myocytes. J Biol Chem 282: 1152-1160, 2007.

46. Li X, Lonard DM, Jung SY, Malovannaya A, Feng Q, Qin J, Tsai SY, Tsai MJ and O'Malley BW: The SRC-3/AIB1 coactivator is degraded in a ubiquitin- and ATP-independent manner by the REGgamma proteasome. Cell 124: 381-392, 2006.

47. Murakami Y, Matsufuji S, Kameji T, Hayashi S, Igarashi K, Tamura T, Tanaka K and Ichihara A: Ornithine decarboxylase is degraded by the $26 \mathrm{~S}$ proteasome without ubiquitination. Nature 360: 597-599, 1992.

48. Poizat C, Sartorelli V, Chung G, Kloner RA and Kedes L: Proteasome-mediated degradation of the coactivator p300 impairs cardiac transcription. Mol Cell Biol 20: 8643-8654, 2000.

49. Sheaff RJ, Singer JD, Swanger J, Smitherman M, Roberts JM and Clurman BE: Proteasomal turnover of $\mathrm{p} 21 \mathrm{Cip} 1$ does not require p21Cip1 ubiquitination. Mol Cell 5: 403-410, 2000. 